\title{
A representação da surdez na literatura: vivências e experiências de surdos e familiares de surdos
}

\author{
Bianca Silva Lopes Costa ${ }^{1}$ \\ Sátila Souza Ribeiro²
}

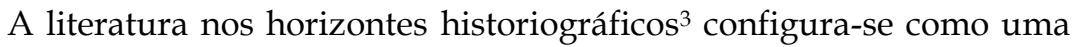
significativa fonte de análise das diferentes visões de mundo que o homem apresenta em cada tempo e espaço. Nesse sentido, a literatura produzida por surdos e pessoas que convivem diretamente com a surdez constitui-se como uma importante fonte histórica para a compreensão das representações que esses sujeitos possuem a respeito de sua maneira própria de estar no mundo, de significar simbolicamente um estatuto e uma posição.

Além disso, as produções literárias desses sujeitos podem viabilizar o entendimento acerca de um determinado tempo histórico, pois a expressão literária pode ser tomada como uma forma de representação social e histórica, sendo testemunha excepcional de uma época, pois se constitui em um produto sociocultural, um fato estético e histórico, que representa as experiências humanas, os hábitos, as atitudes, os sentimentos, as criações, os pensamentos, as práticas, as inquietações, as expectativas, as esperanças, os sonhos e as questões diversas que movimentam e circulam em cada sociedade e tempo histórico (Sevcenko, 2003).

A literatura surda é exígua, não havendo uma grande quantidade de produções realizadas por surdos de forma escrita em língua portuguesa. No entanto, atentando-se para a literatura surda na perspectiva da língua de sinais, a qual é viso-gestual, percebe-se uma significativa produção de poesias, histórias e contos sinalizados. Principalmente devido ao desenvolvimento das tecnologias, tem sido possível o registro dessas produções sinalizadas em vídeos e outros

\footnotetext{
${ }^{1}$ Doutoranda em educação e professora da Secretaria de Educação do Estado da Bahia, Salvador, BA, Brasil. (Dorcid.org/0000-0002-5956-2417. E-mail: biancalscosta@gmail.com

${ }^{2}$ Doutoranda em educação e professora de Língua Brasileira de Sinais (Libras) da Universidade Federal do Recôncavo da Bahia (URFB), Cruz das Almas, BA, Brasil. (Dorcid.org/0000-0002-4695-4841. Email: satila@ufrb.edu.br

${ }^{3}$ Para um aprofundamento das relações entre história e literatura ver Burke (1997). A obra traz um estudo do movimento dos Annales e seus impactos para a produção historiográfica, a qual se abre para novas fontes, novos campos (como a literatura) e novas abordagens.
} 
meios. Os usuários da língua de sinais têm utilizado a escrita dos sinais (sign writing), a qual se constitui em uma forma de registro das línguas de sinais, mas raras são as obras literárias produzidas que utilizam essa escrita. Além disso, um dos problemas é a abrangência do público leitor do sign writing, porque poucos são usuários desse sistema, mesmo na comunidade surda ${ }^{4}$ (Karnopp, 2008).

A percepção da produção de literaturas produzidas por surdos ganha amplitude com o surgimento das comunidades surdas, quando estas passam a compreender a importância e o poder de sua produção imagética e unem-se em torno do propósito de se comunicarem umas com as outras. Nesse contexto é que começam a surgir as produções literárias sinalizadas, baseadas numa língua que utilizava sinais e alicerçadas na própria cultura daqueles surdos. Contudo, com o fortalecimento e hegemonia oralista a partir dos anos e 1880, inicia-se o esfacelamento das comunidades surdas; com isso, ocorre o enfraquecimento das produções literárias surdas e, consequentemente, o desaparecimento do modo literário de sua língua (Porto, 2011).

É importante salientar que o oralismo apregoava que a única forma de salvar o surdo seria através do uso da fala, pela restauração da audição, pois, se ela fosse restaurada, a fala também o seria (Perlin e Strobel, 2008). Essa visão curativa da surdez - segundo a qual os surdos eram vistos como deficientes, e o problema da surdez e suas consequências estavam ligadas ao próprio surdo - prevaleceu por muito tempo, sendo incentivada e estimulada por muitos educadores.

$\mathrm{Na}$ década de 1960, a língua de sinais passa a ter um reconhecimento mais significativo por parte dos educadores e, nesse sentido, passa a ser pensada como um importante instrumento, que permitiria a inclusão do surdo na sociedade. Conforme Obasi (2008), nas últimas décadas, com um delineamento mais amplo sobre o discurso cultural surdo emancipatório, o qual emergiu das narrativas surdas sobre cultura e identidade, orgulho surdo e história surda, percebe-se que as produções literárias que versam sobre a surdez construíram suas narrativas limitadas a modelos conceituais colidentes: modelo clínico versus modelo socioantropológico.

\footnotetext{
${ }^{4}$ Grupo que possui sujeitos ouvintes, familiares de surdos, intérpretes, professores, amigos e outros que participam e compartilham os mesmos interesses em comum em uma determinada localização que podem ser as associações de surdos, federações de surdos, igrejas e outros (Strobel, 2009, p. 6).
} 
No Brasil, as publicações do surdo Jorge Sérgio L. Guimarães, em 1961, constituíram-se como um grande divisor de águas, porque o escritor inaugura uma literatura que afirma que o surdo possui uma identidade própria. A obra Até onde vai o surdo, em que Guimarães narra suas experiências enquanto pessoa surda, incentivou a construção e publicação de várias outras obras literárias concentradas na identidade, e na cultura surda, bem como na língua de sinais (Lebedeff e Madeira, 2015).

Os estudos sobre o sujeito surdo e sua representação na literatura propiciam reflexões e "dependendo dos contextos da história em que os surdos estão inseridos, diferentes olhares de como se interpreta uma história" (Strobel, 2009, p. 3). O conceito de surdez e de pessoa surda passa por mudanças relacionadas às situações contextuais próprias de cada período e, particularmente, de acordo com as experiências dos próprios sujeitos surdos ou que convivam com pessoas que tenham surdez. Nas últimas décadas, com os avanços no que diz respeito às políticas afirmativas, à aprovação de leis e a incentivos no campo educacional, vem ocorrendo uma difusão de ideologias a respeito das pessoas com surdez que tem enfatizado muito as questões da diferença e não mais da deficiência.

Strobel (2009) define que as representações dos sujeitos na ciência histórica mudam conforme os diferentes olhares: no historicismo, os surdos eram narrados a partir do conceito de deficiência enquanto doença. A educação expressava um caráter clínico terapêutico e de reabilitação em que a língua de sinais era vista como prejudicial aos surdos. Já na história crítica, a autora salienta que os surdos eram narrados a partir das ideias de ajuda/auxílio, ou seja, esses sujeitos eram vistos como "coitadinhos" que precisavam de ajuda para se promover sendo pessoas dependentes. Já na perspectiva da história cultural os surdos são percebidos e se percebem como pessoas com experiências visuais, e suas identidades surdas são múltiplas e multifacetadas.

O presente estudo parte da análise de duas produções literárias que tratam sobre a surdez: Crônicas da surdez, de Paula Pfeifer (2013), e A sonoridade da surdez, de Kátia Maria de Oliveira Franco (2013). Entre as justificativas para a escolha dessas obras, destaca-se a relevância dessas produções para a compreensão de como foram construídas, reelaboradas e reescritas as representações sobre a surdez na literatura de uma pessoa surda, no caso de Pfeifer, que vivencia sua surdez a partir da perspectiva oralista, visto que a autora é surda oralizada, ou 
seja, utiliza da comunicação oral e da leitura labial, e não faz uso da língua de sinais. Sua surdez foi pós-lingual, sendo que a perda de sua audição foi gradativa.

Pfeifer não seria a melhor representação de um surdo oralizado, porque sua surdez foi pós-lingual, a autora já possuía uma relação significativa com a língua portuguesa e, posteriormente, com a perda gradativa da audição, optou pelo uso de aparelho auditivo e procedeu à aprendizagem da leitura labial, considerando-se como uma deficiente auditiva. No entanto, sua obra, como o próprio título já elucida, constituise em Crônicas sobre a surdez, ou seja, Pfeifer percebe e conceitua a surdez a partir de suas experiências. Nesse sentido, ela tece sua narrativa não situando a surdez em relação à língua de sinais e à cultura surda, mas a outras singularidades e especificidades.

Já a experiência de Franco (2013) parte de suas vivências com sua filha, que é surda. A obra traz o retrato de uma mãe que luta em favor da qualidade de vida para sua filha, que nasceu com surdez profunda. $\mathrm{O}$ texto apresenta muitas questões, como medo, preconceito, dificuldades financeiras, traição, crise existencial, solidão, mas também traz solidariedade, lealdade, perdão, amor e fé. Franco (2013) destaca a relevância da língua de sinais e da cultura surda. Em suas próprias palavras, ela salienta que:

O seu silêncio me fez querer ouvir o mundo. Passei a ouvi-lo com os olhos, com o tato, com o toque. Passei a ouvi-lo com o coração. O seu silêncio [...] explodiu em meu peito todos os sons e pude entender outras sinfonias e no meio da dor descobri o verdadeiro amor, pois o teu amor silencioso me fez ver que não preciso gritar para me fazer entender que muitas vezes apenas com o olhar invado outro ser (Franco, 2013, p. 287).

Pfeifer (2013) e Franco (2013) falam sobre a surdez a partir de suas próprias experiências e vivências. O que se torna singular nessas obras e que chamou a atenção para este estudo é a forma como é tecida e vivenciada a surdez, que é composta de modos diversos pelas autoras. Parafraseando Michel de Certeau (1994), é possível dizer que, através da leitura dessas obras, a surdez é experienciada a partir de mil maneiras de fazer, alterando assim os objetos, os códigos, imprimindo intenções, sendo uma realidade dinâmica capaz de cercar-se do novo, dos desafios, das dificuldades para ultrapassar-se, redefinir-se e afirmar-se. 
A análise das obras configurou-se em uma pesquisa empírica explicativa, constituindo-se em um estudo documental, cuja amostra foi composta de duas produções editoriais, livros de literatura brasileira que tratam sobre as vivências com a surdez. Os livros foram selecionados a partir de critérios orientados pelas seguintes premissas: por um lado, obras que ainda não constam em análises de caráter científico; por outro, obras literárias que abordam a surdez a partir de perspectivas diferenciadas no que se refere à vivência com a deficiência. Além disso, os critérios de inclusão para compor a amostra requeriam que os livros de literatura fossem indicados para adolescentes ou jovens, estivessem escritos em língua portuguesa e fossem editados no Brasil.

A metodologia de caráter qualitativo utilizada por este estudo foi a análise documental, à luz da análise crítica do discurso, o que possibilita ao pesquisador perceber o modo como as práticas linguístico-discursivas estão imbricadas com as estruturas sociopolíticas e educacionais mais abrangentes. Conforme Fairclough (1992), na análise crítica do discurso, o discurso é visto como um tipo de prática social, de representação e de significação do mundo. Nesse sentido, a partir dos conceitos e dimensões desse método, será viável a análise de possíveis representações da surdez que foram produzidas nas obras selecionadas, além de valores e identidades que foram representados de forma particular.

Karnopp (2006) argumenta que não se fala de literatura surda como algo estanque, limitado ou até demarcado. Nessa perspectiva, a utilização da análise crítica do discurso possibilita uma investigação em que a literatura surda se aproxima da sociedade, possibilitando não apenas o conhecimento das singularidades desse grupo minoritário para eles mesmos, mas de forma ampla, de maneira que vários indivíduos e grupos possam conhecer as especificidades próprias desses sujeitos.

É relevante salientar que a ênfase na análise do discurso utilizada neste texto está vinculada a uma dimensão produtiva dos discursos que compreende a relevância da língua de sinais para os surdos usuários desta. Compreende também outras formas de comunicação dos sujeitos surdos, ou seja, a oralização, com a qual pessoas com surdez se identificam e se comunicam, por meio da leitura labial e da língua portuguesa em suas modalidades escrita e falada.

Ressalta-se aqui que os discursos concebidos nas literaturas estudadas não estão apenas reproduzindo entidades e relações sociais mais amplas, 
mas também são produtores dessas relações, construindo-as de diversas maneiras. Cada obra posiciona os sujeitos sociais de diferentes maneiras, refletindo e introduzindo mudanças na prática social numa relação dinâmica e histórica (Fairclough, 1992). Os discursos aqui analisados, mesmo sendo contrastantes, são vistos como possibilidades de resistência. As postulações de cada autora evidenciam mudanças, relações, contraposições, que também são produtoras de sentido.

A primeira investida nas obras, iniciando-se pela literatura de Paula Pfeifer (2013), Crônicas da Surdez, possibilitou perceber que o livro foi escrito de forma autobiográfica. Nessa obra, a autora se refere a uma "realidade" anterior e exterior ao texto (a vida da autora), tecendo uma narrativa com perspectiva retrospectiva, cujo assunto tratado é sua vida individual, implicada aí, necessariamente, a identidade da autora cruzada com a deficiência auditiva. Diferentemente de outras obras literárias cujos autores surdos propagam e defendem a língua de sinais e a cultura surda como o cerne na vida dos sujeitos surdos, o livro de Pfeifer ressalta sua surdez enfatizando experiências que perpassam a oralização, a leitura labial e a não utilização da língua de sinais. Nas palavras da própria autora:

Quem é surdo oralizado deve ajudar a desmitificar a ideia errada de que deficiência auditiva = Libras. No meu caso, por exemplo, a língua de sinais não tem utilidade nenhuma. Aprendê-la seria como aprender russo ou chinês: uma língua nova que eu usaria muito raramente (Pfeifer, 2013, p. 28).

A autora Paula Pfeifer nasceu em 1982, no Rio Grande do Sul, surda profunda, ela percebeu sua deficiência ainda na adolescência. No entanto, a aceitação de sua surdez ocorreu muito tempo depois, já na fase adulta, "neguei [...] até chegar naquele ponto em que se torna impossível continuar vivendo como se o elefante branco não estivesse sentado bem no meio da sala" (Pfeifer, 2013, p. 9).

A motivação para escrita do livro decorreu de suas próprias experiências com a surdez e de suas pesquisas para a construção de seu trabalho de conclusão do curso de graduação em Ciências Sociais, no qual abordou a temática da escolha da modalidade linguística pelas famílias de crianças com deficiência auditiva. Por meio do trabalho de pesquisa, a autora à constatou que havia poucos livros de literatura a respeito de surdos oralizados escritos por eles mesmos.

Além disso, como ressalta a autora, as obras que versavam sobre a surdez tratavam a deficiência apenas a partir da "língua de sinais, surdos 
sinalizados, identidade surda, ideologia surda, militância surda, cultura surda, luta pelo poder surdo, ouvintização e outros termos que não fizeram parte da experiência de vida da autora" (Pfeifer, 2013, p. 12, grifo nosso).

O livro possui 149 páginas e é constituído de três partes: a primeira trata sobre o mergulho de Pfeifer no universo da surdez; a segunda trata de crônicas das vivências da autora com a surdez; e a terceira e última parte traz depoimentos diversos de pessoas surdas e suas experiências de vida. Constituído de crônicas, o livro apresenta um estilo narrativo bem demarcado, com fatos cotidianos da vida de Pfeifer e de outras pessoas surdas.

A obra possibilita ao leitor estabelecer interações com os acontecimentos narrados, e porque não dizer, que também, identificações com as ações tomadas pela autora-personagem! A percepção da leitura da obra por completa é de que há um estabelecimento dialógico da autora com seus leitores trazendo fatos íntimos, militantes, exposição de sentimentos de sua vida em relação à surdez, promovendo assim, interação e identificação por parte dos leitores.

A relação da escritora com a deficiência auditiva evidencia efeitos constitutivos de um discurso que é alicerçado em sua identidade social, pensada e experimentada nas suas vivências singulares com a surdez dentro da perspectiva oralista:

Penso que não devemos julgar as escolhas alheias. Cada um sabe o que é melhor para si e cada um de nós tem uma história de vida e uma criação diferentes. [...] não concordo com a militância surda que pensa que as crianças surdas devem servir à Libras (quando o certo é que a língua sirva à criança) e age de modo sorrateiro, enganando a opinião pública e fingindo que os surdos oralizados não existem e não têm os mesmos direitos que os surdos sinalizados. Essa militância é contra o teste da orelhinha, diz que o surdo "de verdade" usa Libras, condena o uso de aparelhos auditivos e implantes cocleares, julga de modo cruel os pais que querem dar ao filho a opção de ouvir (a tecnologia está aí para isso) e ainda divide as pessoas em surdos e Surdos, com $S$ maiúsculo - dando a impressão de que Surdos são, de alguma forma, superiores (Pfeifer, 2013, p. 30-31).

Conforme Fairclough (2008) a constituição discursiva de uma sociedade não emana de um livre jogo de ideias nas cabeças das pessoas, mas de uma prática social firmemente enraizada em 
estruturas sociais concretas, orientando-se para elas. Pfeifer (2013) elucida um discurso alicerçado em vivências muito peculiares de sua vida: sua surdez foi pós-lingual, ou seja, a autora foi perdendo a audição ao longo do tempo, e nesse espaço, ela já tinha aprendido a língua portuguesa na modalidade escrita e oral, fez uso de aparelhos auditivos, ainda que "tardiamente" na concepção da autora, devido a negação de sua surdez por um tempo de sua vida: "foi no segundo ano do ensino médio que pude entender o que se passava comigo. Infelizmente, ainda fiquei um longo tempo negando o fato a mim e a todos ao meu redor depois disso" (Pfeifer, 2013, p. 32). A escritora teve acesso à escola, inclusive ao ensino superior, graduando-se em ciências sociais, e tornou-se funcionária pública após sua aprovação em concurso público.

As condições estruturais de sua vida possibilitaram vivências da autora com a surdez de forma muito particular e específica. Nas palavras de Pfeifer, quando ela deixou de resistir ao uso dos aparelhos auditivos, seu relacionamento com o som mudou e as redescobertas diárias lhes trouxeram satisfação pessoal: "Não havia mais motivo para continuar tentando me convencer a continuar presa no silêncio" (Pfeifer, 2013, p. 47). A autora salienta em sua obra que, na caminhada com a surdez, houve momentos em que

passou pela fase do ódio da palavra SURDA. Hoje, pouco me importa que se refiram a mim como deficiente auditiva ou surda - qualquer dicionário informa que surdo é aquele que não ouve ou ouve pouco por ter deficiência auditiva. Não vejo nem faço distinção entre uma forma e outra; para mim, elas querem dizer a mesma coisa (Pfeifer, 2013, p. 37).

Os discursos de Pfeifer (2013) reverberam de discussões que há muito ocorrem na sociedade a respeito dos conceitos de ser surdo e/ou deficiente auditivo e da comunicação das pessoas com surdez: ser surdo oralizado e não utilizar a língua de sinais; ser surdo bilíngue, comunicando-se das duas formas; ser surdo sinalizado, comunicando-se através da língua de sinais. A autora se assume surda oralizada e enfatiza a importância, na sua opinião, de "que qualquer surdo só tem a ganhar em oportunidades profissionais, educativas e pessoais caso domine o português [...], pelo menos o português escrito" (Pfeifer, 2013, p. 30-31).

Seu discurso encontra-se influenciado pela ideologia de que, ao dominar uma língua oral, o surdo tem a possibilidade de conseguir 
diversas oportunidades na sociedade. As enunciações discursivas da autora elucidam representações de práticas discursivas que se encontram inseridas em outras enunciações de pessoas surdas que se identificam com o uso da oralidade (Chouliaraki e Fairclough, 1999).

Porém, Pfeifer (2013) recontextualiza essas enunciações, na medida em que as incorpora e produz representações de modo distinto. Nas palavras da autora:

a surdez torna as pessoas mais observadoras. A visão fica mais aguçada e você passa a prestar atenção em coisas que antes passavam batido [...]. Além de observar o comportamento alheio, você passa a praticar um "esporte" divertido: fazer leitura labial em lugares públicos sem que as pessoas desconfiem (Pfeifer, 2013, p. 50-51).

Essa identificação, dentro da perspectiva ideológica, não nega a surdez, mas a compreende como uma deficiência, em função da qual não se deve viver, mas procurar transcender. Mesmo com os percalços e obstáculos sociais que enfrentou, sua surdez a manteve firme no propósito de superar os desafios e prosseguir na vida social:

As implicações sociais, emocionais e econômicas da surdez são muitas. O segredo da minha paz de espírito é conseguir lidar com todas elas de maneira mais leve possível, me esforçando para levar na esportiva as situações (Pfeifer, 2013, p. 55).

A obra Crônicas da surdez evidencia que a surdez pode ser vivenciada conforme as singularidades de cada sujeito social. Ao discorrer sobre suas vivências, a autora evidencia que a oralização, no seu caso, ampliou muitas possibilidades e viabilizou seu processo de inclusão na sociedade. Suas produções discursivas ressaltam que há uma diversidade e heterogeneidade na surdez, e que a deficiência não pode ser concebida apenas a partir do "estereótipo-padrão de que todo surdo usa Libras e vive exclusivamente em uma comunidade de surdos no qual o único modo de comunicação possível é a língua de sinais" (Pfeifer, 2013, p. 27).

A autora evidencia em sua obra que, ao aceitar sua surdez com mais resiliência e otimismo, conseguiu se adaptar à deficiência auditiva. Nesse sentido, Pfeifer (2013, p. 48) aconselha seus leitores, principalmente os surdos, ressaltando que "quem não ouve tem a obrigação de se informar - sobre sua deficiência, sobre tecnologia, sobre legislação, sobre saúde auditiva. Hoje em dia não há desculpa para a ignorância. Informação é 
poder". Observam-se, nos discursos de Pfeifer, enunciações discursivas incentivadoras de busca pela mudança, de empoderamento.

Pfeifer busca tirar o melhor partido das palavras, a fim de que a forma adapte-se perfeitamente ao que deseja expressar, e essa adaptação não é texto qualquer, é um texto artístico. A autora manipula a palavra com arte, como escritora, ela "não quer apenas que o texto traga indícios de uma realidade e sim uma coisa complexa, um instrumento que vai mostrar, vindo do subconsciente, uma outra realidade" (Camargo, 1984, p. 10), a qual se pretende mudar e pela qual se deve lutar.

Pfeifer (2013) textualiza discursivamente a surdez enunciando uma identidade social que, por sua vez, é materializada em sua vivência, ou seja, suas práticas sociais elucidadas em sua obra foram e são determinadas por sua posição dentro da sociedade enquanto surda. Essas práticas discursivas visam fazer reconhecer uma identidade social, exibir uma maneira própria de estar no mundo, significar simbolicamente um estatuto e uma posição (Chartier, 2002).

A organização retórica de seu texto como um todo evidencia uma prática que visa à transformação das relações de dominação que ocorrem na sociedade. Por ser constituída em sua grande maioria de pessoas ouvintes, a sociedade tem sido erigida dentro dos moldes das pessoas que ouvem. No entanto, as práticas da autora não são apenas de resignação, mas de enfrentamento, superação, há transformação em seu discurso. Como afirma Fairclough (2008, p. 117):

A transformação aponta a luta ideológica como dimensão da prática discursiva, uma luta para remoldar as práticas discursivas e as ideologias nelas construídas no contexto da reestruturação ou da transformação das relações de dominação.

Não há um assujeitamento do discurso de Pfeifer aos discursos mais amplos sobre a relação ouvintes versus surdos, pelo contrário, há referências a mudanças e resistência aos modelos constituídos. A obra configura-se em um texto militante e persuasivo no que diz respeito às ideias da autora com relação a surdez e a oralização. O discurso de Pfeifer apresenta-se como um modo de ação, uma forma pela qual a autora age sobre o mundo e sobre os outros sujeitos. Uma forma de representação, pois nele valores e identidades são representados de forma particular. As enunciações discursivas de Pfeifer elucidam posicionamentos em relação à surdez refletindo e introduzindo mudanças na prática social, numa relação dinâmica e histórica (Magalhães, 2001). 
Por sua vez, a obra A sonoridade da surdez, de Franco (2013), trata do grande sonho da mãe: realizar o implante coclear para a sua filha, dando "o direito do surdo ouvir [...], mas que ainda tem muitos mitos que impedem de aumentar a quantidade de pessoas a serem beneficiadas por tão esplêndida tecnologia" (Franco, 2013, p. 10).

Kátia Maria de Oliveira Franco é ouvinte. Uma mãe que luta, com todas as suas forças para não privar sua filha surda de tudo o que o mundo tem a lhe oferecer. Natural de Palmeiras (BA), cidade localizada na Chapada Diamantina, e residente em Salvador/Bahia. A autora é terapeuta e professora de Libras. Em sua adolescência escrevia poesias.

O livro selecionado para o estudo possui 288 páginas, divididos em 19 momentos que vão desde a descoberta da surdez, o sonho do implante coclear, a descoberta da língua de sinais, a sua alegria em virtude de a filha poder entrar na escola, entre outras passagens, até o momento em que a autora diz: "O seu silêncio me fez ouvir o mundo" (Franco, 2013, p. 11).

Franco teve suas poesias publicadas em duas edições pelo jornal A Tarde, em 1978 e 1979, e participou de três livros de poesia. Em 1984, a autora casa-se e tem três filhos - Rafael, Claudia e Gabriel -, sendo que a sua filha, em virtude da rubéola durante a gestação, nasceu com surdez profunda, fato que trouxe mudanças em sua caminhada de vida. Em 2013, lançou seu primeiro livro de crônicas - Casos e causos e sua autobiografia, registrada por meio do livro $A$ sonoridade da surdez. Também participou do livro de crônicas Canja poética, lançado em outubro de 2015, no Rio de Janeiro.

Numa perspectiva contextualizada, que demonstra uma concepção de "normalidade" da surdez, foi possível perceber na obra de Franco (2013) o apelo pela conscientização da surdez como uma diferença e não como deficiência. Nas palavras da autora:

Hoje, neste momento pude entender que quem precisaria aprender era eu e não a Claudia, quem precisava escutar era eu e não ela. Pois, quando ela se privou de ouvir pude abrir meus olhos e meu coração para todos os outros sons e, que por termos a audição "perfeita" não sabemos ouvir (Franco, 2013, p. 286).

A autora outorga uma necessidade de afirmar a surdez de sua filha a partir da diferença "pelo fato de ouvir não aprendemos a escutar" (Franco, 2013 p. 287). Nesse sentido, enfatiza que a diferença que a filha apresentava fez com que ela (mãe) ouvisse a vida e escutasse o outro. 
Ela expressa sua história de vida juntamente com a de sua filha surda, apresentando espaços e vivências, cujas lutas e resistências emaranham a obra, traduzindo em sua produção literária, não apenas um grito, mas inconstâncias, sensibilidade, alternativas, lados.

Sem saber que identidade reconhecer para Claudia, Franco demonstra um estado de angústia em relação às possibilidades de vida em sociedade que se apresentavam para sua filha, podendo ser julgada e considerada inferior pelos outros. Por isso, conforme se lê em sua obra autobiográfica, Franco levanta a bandeira de luta e passa a buscar alternativas para a inclusão de sua filha.

Vale ressaltar que a obra de Franco não pode ser considerada a melhor representação para o surdo sinalizado, haja vista que a escritora não é surda, e sim a filha. No entanto, não se pode retirar a propriedade da autora em relação à surdez, já que a experiência de Franco com sua filha surda é singular e representativa das lutas dos sujeitos surdos e familiares de surdos na valorização e no reconhecimento social.

Ao falar de suas vivências com a surdez de sua filha, Franco (2013) suscita em seu discurso uma possível "pretensão" de uma produção literária de autoajuda, proporcionando ao leitor uma relação entre este e a pessoa com surdez, na tentativa de, em confronto com a situação evidenciada na obra, proporcionar ao leitor a possiblidade de ressignificação existencial nas adversidades.

A obra posiciona a mãe de uma filha surda - uma ativista pela causa - e consolida seus posicionamentos em relação à surdez, traduzindo suas reflexões sobre a surdez e a militância. A obra de Franco traz fórmulas predefinidas e contém entre seus componentes básicos: a proposição de método ou técnica para o alcance de sucesso material; a idealização da realização pessoal de sua filha; e uma dimensão transcendental que liga a realização do indivíduo a um ordenamento moral do mundo (Bosco, 2001).

Franco traz à tona em sua literatura questões existenciais quando recorda, por exemplo, o momento da confirmação, via médico, da surdez de sua filha, e por assim demonstrar o "luto do filho indesejado" e deixa claro certa "indignação" no que diz respeito à sua própria pessoa. Nas palavras da autora, como uma pessoa tão falante como ela poderia gerar uma filha surda, privada do som, inacreditavelmente privada do som da sua voz enquanto mãe (Franco, 2013). 
Percebe-se, a partir desse discurso, a urgência da autora em apresentar logo de início a deficiência de sua filha em moldes discursivos de reivindicações de lugares, de impasses quanto à afirmação de uma possível identidade, de luta por direitos, de conflitos, de alternativas. No caso de Franco, ela apostou na aprendizagem da língua de sinais por sua filha, devido à falta de opção que havia no contexto social em que elas viviam. Primeiramente, tomou a decisão pelo implante coclear, ${ }^{5}$ o qual não se mostrou uma alternativa possível. Depois apostou no aparelho auditivo, o qual também não tinha potencial de ajudar muito Claudia, por causa da profunda limitação de sua audição, e, por fim, a aprendizagem da língua de sinais.

$\mathrm{Na}$ estrutura analítica da crítica do discurso, as discussões de Fairclough (2005) elucidam que há discursos nos quais estão presentes situações conflitivas quanto à vida. Contudo, é importante ressaltar que nesses mesmos discursos há o prenúncio de fórmulas discursivas que apresentam argumentos enunciativos com soluções e resoluções desses mesmos conflitos. Um discurso que desperta o leitor para questões que dizem respeito à esperança, à luta e à defesa de direitos em razão de formas particulares de vida social (Fairclough, 2005).

A obra de Franco evidencia a surdez como uma situação passível de mudança e de enfrentamento - e, por conseguinte, de solução. Encontram-se presentes em $A$ sonoridade da surdez enunciações discursivas nas quais ocorre a junção de componentes discursivos que delineiam relacionamentos saudáveis e dialógicos, mesmo em um contexto negativo no que diz respeito à vida social, em função da surdez. Há ênfase e defesa argumentativa de possibilidades resolutivas, a partir da busca por recursos para que se chegue a uma solução.

Conforme Santos e Cunha (2015), a responsabilização crescente do indivíduo por seu destino, sobretudo a partir da valorização da personalidade e da ideia de controle sobre si vinculada à racionalidade instrumental, faz com que esses indivíduos passem a ser cada vez mais sujeitos da transformação de si. No caso da obra de Franco, ela narra sua própria vida com a da sua filha, enunciando os aspectos mais dramáticos, que se configuram como narrativas do sofrimento de

\footnotetext{
${ }^{5}$ Aparelho eletrônico que, por meio cirúrgico, é colocado dentro do ouvido para captar o som, sendo capaz de estimular diretamente o nervo auditivo, causando sensações sonoras, com a função de restaurar a audição nos pacientes com surdez profunda que não têm benefício com aparelhos auditivos convencionais (Franco, 2013).
} 
ambas, os percalços enfrentados pelas duas, principalmente dela (Franco) enquanto mãe, na busca por situações que sejam cruciais e fundamentais para mudanças em suas vidas. Daí o fato de evidenciar, em sua escrita literária, posições para a construção de uma identidade e reflexão das questões em jogo, ao expressar formas de pensar e de agir e uma ideologia que se pretende levar ao conhecimento dos leitores que integram a sociedade (Pesavento, 2005).

Franco deixa claro em sua obra que não compreendia o "mundo da sua filha", ao passo que não aceitava ter gerado uma filha surda, por isso buscou recursos para compreender, de fato, o que significava a surdez e o que a filha sentia. A autora deixa evidente que, quando as pessoas questionavam se Claudia era surda, logo respondia que não, e sim deficiente auditiva, "parecia que mudando o termo, amenizava a dor" (Franco, 2013, p. 29).

No discurso da autora, percebe-se certa oscilação: ora aceitava a filha como surda, ora como deficiente auditiva. Vale salientar que existe uma diferença entre esses termos: surdo e deficiente auditivo, segundo Quadros e Karnopp (2004) e Bisol e Valentini (2011). O primeiro conceito refere-se à surdez entendida como uma condição que "consubstancia experiências visuais do mundo" (Quadros e Karnopp, 2004 , p. 10). Por sua vez, são consideradas surdas aquelas pessoas que se identificam enquanto tal. Assim,

a identificação dos surdos situa-se culturalmente dentro das experiências visuais. Entende-se cultura surda como a identidade cultural de um grupo de surdos que se define enquanto grupo diferente de outros grupos (Quadros e Karnopp, 2004, p. 10).

Dentro do contexto histórico da cultura surda, o deficiente auditivo pode ser considerado aquele que tem uso da audição dificultada parcialmente. No entanto, segundo Perlin (2000), esse grupo não se enquadra na cultura surda, visto que possuem uma situação que pode ser solucionada pelo simples aumento de volume de som e/ou aparelhos de amplificação $^{6}$ sonora. Conforme, a mesma autora, considera-se pessoa surda aquela que, tendo a perda auditiva, compreende e interage com o

\footnotetext{
${ }^{6}$ Para um aprofundamento acerca das diferenças conceituais entre surdez e deficiência auditiva, ver Perlin (2000). Ver também o Decreto $\mathrm{n}^{\circ} 5.626$, de 22 de dezembro de 2005, que fala sobre a deficiência auditiva em seu art. $2^{\circ}$ : "perda bilateral, parcial ou total, de 41 decibéis $(\mathrm{dB})$ ou mais, aferida por audiograma nas frequências de $500 \mathrm{~Hz}, 1.000 \mathrm{~Hz}, 2.000 \mathrm{~Hz}$ e $3.000 \mathrm{~Hz}$ ".
} 
mundo por meio de experiências visuais, manifestando sua cultura principalmente pelo uso da língua brasileira de sinais (Libras).

Franco (2013) escreve no formato de autobiografia, utiliza sempre a primeira pessoa do singular, destacando fatos contextualizados do antes e depois. Elucida uma narrativa existencial, demonstrada a partir daí a sua relação com a surdez. Defende o uso da língua de sinais, bem como a oralização, haja vista que buscava também introduzir a oralização na sua filha, investindo, em muitas vezes, em tratamentos com fonoaudiólogos, com vistas a possibilitar que a menina falasse.

Franco demonstra uma volubilidade em sua narrativa, principalmente quando evidencia a relevância da Libras para a inclusão e acessibilidade linguística de Claudia na comunidade surda. Isso aconteceu apenas quando a menina completou 15 anos de idade, visto que não havia escola especial em sua cidade natal. Franco teve de buscar auxílio em Salvador, capital da Bahia, conseguindo assim que sua filha estudasse em uma escola especial e conquistasse o direito de ouvir e falar.

A obra elucida a valorização do sujeito surdo e a conquista por direitos como a aprendizagem da língua portuguesa como segunda língua na modalidade escrita e a língua brasileira de sinais como primeira língua. Provavelmente, a dificuldade do acesso linguístico para Claudia, no início da sua caminhada de vida, se deve a uma estatística bastante curiosa: cerca de $90 \%$ das crianças surdas são filhas de pais ouvintes, e estes, por sua vez, desconhecem a língua de sinais (Silva, 2015).

Essa análise buscou compreender a representação da surdez na literatura a partir de vivências e experiências de surdos e familiares de surdos. Nesse sentido, a partir da análise discursiva das obras Crônicas da surdez, de Paula Pfeifer (2013), e A sonoridade da surdez, de Kátia Maria de Oliveira Franco (2013), foi possível perceber que, para as autoras, a surdez se apresenta como uma experiência heterogênea e multifacetada. As vivências dos sujeitos surdos e de seus familiares representadas nas obras literárias constituem-se como únicas e próprias. A realidade da surdez foi construída e tecida a partir de modos muito próprios e práticas que visavam fazer reconhecer uma identidade social, exibir uma maneira singular de estar no mundo, de significar simbolicamente um estatuto e uma posição. As formas institucionalizadas e objetivadas foram ressignificadas de forma a constituir vivências redimensionadas, que possibilitaram visibilidade e perpetuação dos modos de sujeitos que se relacionam com a surdez. 
As visões de mundo enunciadas discursivamente nas obras indicam um tempo e espaço experienciados pelos sujeitos que vivem e convivem com a surdez buscando formas de superação de limitações, de reconhecimento de capacidades, de defesa e reivindicação de direitos, em um contexto histórico contemporâneo que reconhece e legitima especificidades de um grupo minoritário que por muito tempo foi reprimido ou pensado a partir de ideologias dominantes.

A expressão literária pode ser tomada como uma forma de representação social e histórica. Destarte, as obras de Franco e Pfeifer constituem-se como testemunhas excepcionais de uma época, a atual, em que as experiências dos sujeitos surdos e das pessoas muito próximas da surdez - ou seja, seus hábitos, atitudes, sentimentos, criações, pensamentos, práticas, inquietações, expectativas, esperanças, lutas, sonhos e outras questões que movimentam e circulam na sociedade contemporânea - destacam princípios e valores que oscilam conforme as condições socioculturais contextuais. Observa-se que um espaço histórico não implica definidamente uma posição monolítica e linear dos sujeitos sociais, porque na experiência e na vivência com a surdez, processos diversos de produção do ser e do vir a ser são modificados conforme as aspirações e necessidades próprias desses mesmos sujeitos (Sevcenko, 2003).

Os discursos que se enunciam nas obras analisadas demonstram também um campo de tensão, no qual são explicitadas tanto as condições materiais de vida dos sujeitos surdos como os modos de viver, as ideias, as sensibilidades, as utopias, os projetos e as expectativas que o próprio viver com a surdez comporta e enseja, "muitas vezes dissimulando as contradições da trama histórica. Tratando-se, também, da possibilidade de tomar o não acontecido para recuperar o que aconteceu" (Pesavento, 2005, p. 22).

As obras literárias analisadas elucidam discursos que trazem à tona questões condizentes com as necessidades e lutas próprias desse grupo minoritário. Trata-se de textos literários que expressam tentativas de representação dos novos tempos e das relações socioculturais das pessoas com surdez e os ouvintes. Para além disso, as produções literárias das autoras trazem contribuições significativas para as discussões acerca da literatura, surdez, sociedade e contemporaneidade.

Desse modo, esta análise permitiu concluir que as formas de arte imbricadas nessas produções literárias são fruto da característica que 
apresentam, a surdez - sendo essa um marcador cultural existente na sociedade -, tanto pelo fato de produzirem literaturas sendo surdos ou familiares de surdos, como pelo conteúdo de suas produções, alcançando um caráter informativo e reflexivo. Informativo, ao oferecer mensagens desde a sua construção até o momento em que são partilhados pelo público, e reflexivo, por possibilitarem ao leitor pensar sobre as informações nelas contidas.

\section{Referências}

BISOL, Cláudia; Valentini, Carla Beatris (2011). Surdez e deficiência auditiva: qual a diferença? Objeto de Aprendizagem Incluir. Caxias do Sul: UCS; FAPERGS. Disponível em: <https://goo.gl/2g3mMw>. Acesso em: 29 dez. 2016.

BOSCO, Angelo Marcos (2001). Sucessos que não ocorrem por acaso: literaturas de autoajuda. Dissertação (Mestrado em Sociologia) - Universidade Estadual de Campinas, Campinas, SP.

BURKE, Peter. A Escola dos Annales (1929-1989): a Revolução Francesa da historiografia. São Paulo: UNESP, 1997

CAMARGO, Oswaldo de (1984). O estranho. São Paulo: Roswitha Kempf.

CASTRO JUNIOR, Gláucio de (2011). A educação de surdos no Distrito Federal: perspectivas da política de inclusão. Monografia (Especialização em Desenvolvimento Humano, educação e inclusão escolar - Universidade Aberta do Brasil, Universidade de Brasília, Brasília.

CERTEAU, Michel de (1994). A invenção do cotidiano: artes de fazer. Petrópolis: Vozes.

CHARTIER, Roger (2002). A história cultural: entre práticas e representações. Lisboa: Difel.

CHOULIARAKI, Lilie; FAIRCLOUGH, Norman (1999). Discourse in late modernity: rethinking critical discourse analysis. Edinburgh: Edinburgh University Press.

FAIRCLOUGH, Norman (1992). Discourse and social change. Oxford: Blackwell; Cambridge: Polity Press.

FAIRCLOUGH, Norman (2008). Discurso e mudança social. Tradução Izabel Magalhães. Brasília: Editora da UnB. 
FAIRCLOUGH, Norman (2000). Discourse, social theory and social research: the case of welfare reform. Journal of Sociolinguistics, Medford, v. 4, n. 2, p. 163-195, May.

FAIRCLOUGH, Norman (2005). Critical discourse analysis as a method in social scientic research. In: WODAK, Ruth; MEYER, Michael (Org.). Methods of critical discourse analysis. 2. ed. Londres: Sage, p. 121-138.

FRANCO, Kátia Maria de Oliveira (2013). A sonoridade da surdez. São Paulo: Biblioteca 24 Horas.

KARNOPP, Lodenir (2008). Literatura surda. Florianópolis: Editora da UFSC. (Coleção Letras Libras Literatura Visual).

KARNOPP, Lodenir (2010). Produções culturais de surdos: análise da literatura surda.

KARNOPP, Lodenir (2006). Literatura surda. Educação Temática Digital, Campinas, v. 7, n. 2, p. 98-109.

LEBEDEFF, Tatiana Bolivar; MADEIRA, Diogo de Souza (2015). As crônicas de Jorge Sérgio L. Guimarães e as representações da surdez entre as décadas de 1950 e 1960. Revista Reflexão e Ação, Santa Cruz do Sul, v. 23, n. 3, p. 173-192.

MEDEIROS, Cabral (2016). Literatura visual/surda: relevância e encorajamento à sua produção nas escolas. In: CONGRESSO INTERNACIONAL DE EDUCAÇÃO INCLUSIVA - CINTEDI, 2., JORNADA CHILENA BRASILEIRA SOBRE EDUCAÇÃO INCLUSIVA, 2., 16-18 nov. Anais... Campina Grande: Realize. Disponível em: <https://goo.gl/Wb9ZKK>. Acesso em: 28 nov. 2016.

MAGALHÃES, Célia Maria (Org.) (2001). Reflexões sobre a análise crítica do discurso. Belo Horizonte: Editora da UFMG.

PERLIN, Gládis; STROBEL, Karin (2008). Fundamentos da educação de surdos. Apostila de disciplina. Florianópolis, Licenciatura e Bacharelado em Letras/Língua Brasileira de Sinais, UFSC. On-line. Disponível em: <https://goo.gl/oVRFkt>. Acesso em: 10 jan. 2016.

PERLIN, Gládis (2000). Identidade surda e currículo. In: LACERDA, Cristina B. F. de; GÓES, Maria Cecília R. de (Org.). Surdez: processos educativos e subjetividade. São Paulo: Lovise.

PESAVENTO, Sandra Jatahy (2005). História \& história cultural. 2. ed. Belo Horizonte: Autêntica.

PFEIFER, Paula (2013). Crônicas da surdez. São Paulo: Plexus.

PORTO, Shirley (2011). Literatura visual. In: FARIA, Evangelina Maria Brito de, ASSIS, Maria Cristina de (Org.). Língua portuguesa e libras: teorias e práticas. João Pessoa: Editora da UFPB. v. 3. 
OBASI, Chijioke (2008). Seeing the deaf in "deafness". Journal of Deaf Studies and Deaf Education, v. 13, n. 4, p. 455-465, 1 Oct.

QUADROS, Ronice Muller de; KARNOPP, Lodenir Becker (2004). Língua brasileira de sinais: estudos linguísticos. Porto Alegre: Artmed.

SANTOS, Arci Gardênia Alves; CUNHA, Eduardo Leal (2005). O discurso de autoajuda em uma revista semanal de informação. Psicologia $\mathcal{E}$ Sociedade, v. 27, n. 3, p. 689-699. Disponível em: <https://goo.gl/5XV918>. Acesso em: 20 abr. 2017.

SEVCENKO, Nicolau (2003). Literatura como missão: tensões sociais e criação cultural na Primeira República. São Paulo: Companhia das Letras.

SILVA, Barboza P. da (2015). A inclusão do estudante surdo no ensino superior: das percepções de estudantes surdos e seus professores às práticas de sala de aula. Lisboa: ULHT; Instituto de Educação ULisboa.

STROBEL, Karin (2009). As imagens do outro sobre a cultura surda. 2. ed. rev. Florianópolis: Editora da UFSC.

Recebido em 29 de maio de 2017.

Aprovado em 16 de janeiro de 2018.

\section{resumo/abstract/resumen}

\section{A representação da surdez na literatura: vivências e experiências de surdos e familiares de surdos}

Bianca Silva Lopes Costa

Sátila Souza Ribeiro

O presente estudo teve como principal objetivo analisar como foram construídas, reelaboradas e reescritas as representações sobre a surdez na literatura produzidas por sujeitos surdos e familiares de surdos. Além disso, identificar marcadores sócio-históricos e ideológicos nas produções discursivas de ambas literaturas. Para tal, recorreu-se à análise das produções literárias que tratam sobre a surdez, como as Crônicas da surdez, de Paula Pfeifer (2013), e A sonoridade da surdez, de Kátia Maria de Oliveira Franco (2013). O estudo destaca a relevância de tais produções para a compreensão acerca dessas representações na literatura. Paula Pfeifer (2013) é surda oralizada e vivencia sua surdez em um contexto oralista, diferentemente de Kátia Franco (2013), que, para sua produção discursiva, parte de suas vivências com a sua filha, que nasceu com surdez profunda e passou a utilizar a língua brasileira de sinais (Libras) como forma de comunicação. As autoras falam sobre a surdez a partir de suas próprias experiências e vivências. Estas análises constituíram-se em uma pesquisa 
empírica explicativa, cuja amostra foi composta de duas produções editoriais, livros de literatura brasileira que tratam sobre as vivências com a surdez. A metodologia de caráter qualitativa utilizada por este estudo foi a análise documental, à luz da análise crítica do discurso, o que permitiu a compreensão acerca das representações da surdez tecidas nas obras, bem como a identificação de marcadores culturais. Concluiu-se que este estudo possibilitou um maior aprofundamento teórico sobre conhecimentos acerca das vivências com a surdez e elucidou discursos que trazem à tona questões condizentes com as necessidades e lutas próprias desse grupo minoritário.

Palavras-chave: representação, surdez, literatura.

\section{The representation of deceit in literature: living and experiences of deaf and family of deaf}

Bianca Silva Lopes Costa

Sátila Souza Ribeiro

The present study had as main objective to analyze how the representations about deafness in the literature produced by deaf subjects and relatives of the deaf were constructed, reworked and rewritten. In addition, to identify markers, socio-historical and ideological in the discursive productions of both literatures. For this, we used the analysis of literary productions that deal with deafness, such as the Crônicas da surdez, of Paula Pfeifer (2013), and A sonoridade da surdez, of Kátia Maria de Oliveira Franco (2013), the study highlights the relevance about to understand these representations in the literature. Paula Pfeifer (2013) is oralized deaf and experiences her deafness in an oralistic context, unlike Kátia Franco (2013) who for her discursive production parts of her experiences with her daughter who is born with profound deafness and uses the Brazilian Sign Language (Libras) as a form of communication. The authors talk about deafness from their own experiences and particular stories with deafness. This analysis consisted of an explicative empirical research, whose sample was composed of two editorial productions, Brazilian literature books dealing with experiences with deafness. The qualitative methodology used by this study was the documentary analysis, in light of the critical discourse analysis. This analysis allowed us to understand the representations of deafness mentioned in the works, as well as the identification of cultural markers in the analyzed works. It was concluded that this study made possible a deeper understanding about the experiences with deafness and elucidated discourses that bring up issues that are in keeping with the needs and struggles of deaf communities.

Keywords: representation, deafness, literature. 


\section{La representación de la sordera en la literatura: vivencias y experiencias de sordos y familiares de sordos}

Bianca Silva Lopes Costa

Sátila Souza Ribeiro

El presente estudio tuvo como principal objetivo analizar la forma en que fueron construidas, reelaboradas y la reescritura de las representaciones de la sordera en la literatura producidas por sujetos sordos y familiares de sordos. Además, identificar marcadores socio-históricos e ideológicos en las producciones discursivas de ambas las literaturas. Para ello, se utilizó el análisis de las producciones literarias que tratan sobre la sordera, como Las crónicas de la sordera, de Paula Pfeifer (2013), y La sonoridad de la sordera, de Kátia Maria de Oliveira Franco (2013), el estudio destaca la relevancia de tales producciones para la comprensión acerca de estas representaciones en la literatura. Paula Pfeifer (2013) es sorda oralizada y vive a su sordera en un contexto oralista, a diferencia de Kátia Franco (2013) que para su producción discursiva parte de sus vivencias con su hija que nace con sordera profunda y utiliza la Lengua Brasileña de Señales (Libras) como forma de comunicación. Las autoras hablan sobre la sordera a partir de sus propias experiencias y vivencias con la sordera. Este análisis se constituyó en una investigación empírica explicativa, cuya muestra fue compuesta de 02 (dos) producciones editoriales, libros de literatura brasileña que tratan sobre las vivencias con la sordera. La metodología de carácter cualitativo utilizada por este estudio fue el análisis documental y, a la luz del análisis crítico del discurso, tal análisis ha permitido la comprensión acerca de las representaciones de la sordera tejidos de las obras, así como la identificación de marcadores culturales en las obras analizadas. Se concluye que, este estudio posibilitó una mayor profundización sobre conocimientos acerca de las vivencias con la sordera y aclaró discursos que traen a la luz cuestiones que coinciden con las necesidades y luchas propias de estos grupos minoritarios.

Palabras-clave: representación, sordera, literatura. 